\title{
6 \\ To be or not to be? \\ Crisis and the humanities in Germany
}

SIBYLLE BAUMBACH

The humanities are Hamlet. Indeed, there seems to be greater kinship between the German Geisteswissenschaften and Shakespeare's character than might be apparent at first glance: the resemblance does not so much derive from the common (mis-)perception that Hamlet, who personifies the epitome of melancholy and contemplates suicide in the famous speech "To be, or not to be" (Hamlet, 3.1.56), thinks too much and acts too little. In fact, Hamlet does take action and devises a play, designed to corroborate the hypothesis of fratricide. It is Hamlet's hesitation that propels the action, and his character can indeed be seen as embodying both the eternal crisis as well as the productivity of this crisis (after all, Hamlet is one of Shakespeare's most popular plays, frequently performed and thus continuously revived across the globe) that has come to be associated with the Geisteswissenschaften.

Considering that a crisis marks a turning point, "both a moment of balance and a moment of unbalance, of decision and of indecision, of determination ... and of indetermination" (Brown 1997: 10), and points towards the end of an old and the beginning of a new order, it can be regarded as productive: crises inspire changes, which might lead to the renewal of disciplines or prompt the development of (new) areas, such as, for instance, the study of culture or Kulturwissenschaften, which emerged from the crisis in the humanities in the 1990s (see Metten 2016: 5) as a field that seemed to respond to the increasing demand for applicability and connectivity in both research and teaching (cf. Wissenschaftsrat 2006: 13).

In terms of their productivity, crises are indispensable for innovation and growth. This might explain why the crisis-in-the-humanities discourse seems to have been carefully sustained over the past decades, partly driven by the humanities themselves. In fact, the 'eternal crisis' (Gumbrecht 2015) seems to have become a modus operandi for the humanities that helps draw attention to the specificities of the Geisteswissenschaften and allows them to continually re-invent and, ultimately, to renew themselves. Though the crisis rhetoric still seems to dominate much of the discourse revolving around the humanities, 
it is safe to say that major cuts and constraints of the German Geisteswissenschaften have been successfully averted thanks to political interventions and specific funding schemes which were introduced to counteract the growing trend towards applicability and commercialization.

Before analysing the current state of the humanities in Germany, a short overview of their development will serve to elucidate the genesis of some of the struggles that have shaped and continue to shape the Geisteswissenschaften.

While the list of disciplines subsumed under Geisteswissenschaften varies, the latter are generally understood to embrace disciplines rooted in hermeneutic methods (in contrast to the experimental sciences). These tend to include philosophy, linguistics and literary studies, history, area studies, theology, anthropology, media studies, art history, theatre studies, and music studies, while educational science, psychology, social science, economics, and law are subsumed under social and behavioural sciences. Though the human sciences and social sciences represent different subject areas, Geistes- und Sozialwissenschaften have often been combined in recent funding programmes (DFG 2017b: 172).

Like in other countries, the crisis of the humanities in Germany is grounded in a crisis of legitimization, which took root in the heavily contested yet still persistent trend to distinguish between two (cf. Snow 1998 [1959]) or three, including the social sciences (cf. Lepenies 1988), different 'cultures' of research. While the German terms Geisteswissenschaften (human sciences, or, literally, the sciences of the 'mind' (Geist)) and Naturwissenschaften (natural sciences), as popularized by Wilhelm Dilthey, imply a radical split between Geist (which can be translated as 'mind', 'self', 'psyche', or 'consciousness') and nature, they also underscore the fact that the 'humanities' are a 'science amongst sciences' (Wissenschaftsrat 2006: 14), grounded in the same academic traditions as the natural and also the social sciences (Sozialwissenschaften). This approach precludes the inevitable problem of positioning, for instance, psychology or mathematics in the intricate hurly-burly of different 'research cultures'. Furthermore, as Jürgen Mittelstrass argued, it is a common misconception that the natural sciences objectify nature: just like the 'human sciences' (and also the social sciences), they objectify the human mind. In this respect, 'all science is Geisteswissenschaft' (Mittelstrass 2013: 138). Mittelstrass does not suggest a hierarchy of the sciences: instead, this claim emphasizes their mutual foundation in the aim to objectify (human) nature while also pointing to the futile and somehow grotesque endeavour to categorize sciences.

In fact, the (re-)categorization of the humanities marked one of the first symptoms of their crisis. Prompted by the rather vague term Geist and also partly by a misunderstanding of Dilthey's terminology (Bulhof 2012: 159), Heinrich Rickert proposed to refer to the study of the social-historical world as Kulturwissenschaften (cultural studies) rather than Geisteswissenschaften. According to Rickert, the former comprised "all objects of religious studies, 
law, history, philology, economics etc., thus the objects of all Geisteswissenschaften except psychology" (Rickert 1926: 22, my translation). It was not until the late twentieth century, that Kulturwissenschaften, prompted by impulses from sociology (esp. Max Weber, Georg Simmel, and Walter Benjamin) gained ground both as an independent discipline (Kulturwissenschaft) and as a vital movement that liberated the Geisteswissenschaften from the "global crisis of the humanities" (Frühwald et al. 1991: 69). This crisis emerged as a result of the postwar focus on natural sciences and engineering, resulting in new emphasis on applicability (Wissenschaftsrat 2006: 12), rather than appreciating the humanities not only as studia humaniora (Nida-Rümelin 2006: 33), which offers orientation, but as "a comprehension of the world which always seeks to overcome, relativise, and transcend the necessary central anthropological perspective" (Markschies 2006: n.p.).

If there was a hierarchy of the natural sciences and the human science in the nineteenth century, however, it was the Geisteswissenschaften that came first: offering a humanist education and protecting cultural heritage from the cold reasoning of the natural sciences, their immediate utility to society was undisputed and their self-esteem high. In 1920, Ernst Robert Curtius allegedly turned down a professorship at a technical university because he feared that there he might be addressed as 'colleague' by a Professor of Heating and Ventilation (Hornbostel 2014: 103). The neo-humanist ideal, which rendered the Geisteswissenschaften an indispensable element of education, faded with the disenchantment of the world, increased technological progress, and economic growth, which shifted the attention to the natural sciences and engineering. As a consequence, the humanities were forced to reinvent themselves.

They first responded to these new demands for proof of relevance by a theory-boom, which started in the 1960s and reached from structuralism, Marxism, and reader-response theories to deconstruction, new historicism as well as to postcolonial and gender theory. In addition, attempts were made to underscore their relevance by stressing their ostensibly important role in compensating the shortcomings in a technically highly advanced, disenchanted postmodern world. This is suggested, for instance, by Odo Marquard's oftencited claim, "the more modern the world, the more indispensable the humanities" (Marquard 2001: 98, my translation). Though intended to support the Geisteswissenschaften, this statement, in fact, overshadows them by presenting the humanities as ancillary sciences, which fills the gaps left by the triumphal progression of the natural and technical sciences. It suggests that their principal claim to existence derives from their ability to offer the cultural and ethical framework which provides orientation and the means for (critical) selfreflection in a rapidly changing world. While this notion is in itself highly problematic, it went hand in hand with the growing emphasis of the Geisteswissenschaften on the analysis of "culture as the epitome of human activities and forms of life, including developments from the natural sciences and beyond' (Frühwald et al. 1991: 40f., my translation). 
The cultural turn within the humanities countered the trend towards growing abstraction and narrowed the gap between the hermeneutic and the experimental sciences: Kulturwissenschaften ventured to embrace both universal and integrative approaches, thus connecting to the ideal represented by Alexander von Humboldt, who embodied "the personal union of the natural and cultural scientist" (Dill 2013: 83, my translation). As suggested by the Wissenschaftsrat, however, the term 'cultural science' is problematic insofar as it implies an approach to the concept of 'culture' as a unit, rather than as the product of complex processes of societal and cultural differentiation (Wissenschaftsrat 2006: 12f.). Further, the term 'cultural science' implies a dualism between 'culture' and 'nature', which does not do justice to the growing movement towards interdisciplinary research.

The debate revolving around the (inter-)connection of Geistes- and Kulturwissenschaften is indicative of the continuous attempt of the humanities to legitimize their own existence - an attempt that was also reflected in the Year of the Geisteswissenschaften, launched by the Ministry for Research and Education (BMBF) in 2007 to support the humanities, including the cultural and social studies. The aim was noble, i.e. to raise awareness for the specific areas of research in these fields, yet the presentation weak. The slogan of the year, Die Geisteswissenschaften: $A B C$ der Menschheit [The human sciences: ABC of humanity] (Gruner 2007: 67) was impregnated by the discourse on relevance that has been pushing the humanities into an apologetic habitus. For some, the Year of the Geisteswissenschaften marks the worst symptom of an ongoing crisis, as it attests to the need for political (and thus financial) support (Jahraus 2007: 242). However, it was the eighth year in a series of 'science years' launched by the BMBF. Following the years of Computer Science (2006), Physics (2005), and Technology (2004), the Geisteswissenschaften were in fact in the good company of non-crisis-ridden disciplines without being a discipline. And there was the rub: even though previous research years focused on a specific discipline, when it was the turn of the humanities to move centre stage, they could do so only as a group of disciplines. Critics viewed this as "a symptom of disadvantages, a symptom of the crisis in the humanities" (Markschies 2006: n.p.). It might have been due to the underlying Stimmung of 'eternal crisis' that this initiative was partly received as yet another (pseudo-)justification insofar as its initial outline missed the essence of the Geisteswissenschaften by proclaiming that they were concerned with the communication, construction, and remembrance of knowledge (rather than with the reflection of the multiple processes that constitute 'culture') (Gumbrecht 2007: n.p.).

Notwithstanding the somehow infelicitous rhetoric, there was a substantial increase in funding: in 2007, the federal budget for research in the social sciences and humanities was raised by 22 per cent to $€ 44.3$ million (Krieger 2006: n.p.). Whereas before 2007, the BMBF was only marginally engaged in funding research in the Geisteswissenschaften, it launched a new framework 
programme dedicated to support research projects and centres in the humanities, increase their international visibility, and promote interdisciplinary collaboration. This initiative was followed by a second funding programme, which ran from 2012 until 2017 and was designed for the Geistes-, Kultur-, and Sozialwissenschaften (human, cultural, and social sciences), acknowledging these fields as independent yet deeply connected areas of research.

As part of the programme, which provided funding for the support of individual researchers, collaborative projects, and research infrastructures, several international centres in the humanities were established to create international research hubs for specific areas, such as Digital Humanities, support early-career researchers, and improve research infrastructures in these fields. Between 2013 and 2016 alone, around $€ 400$ million were spent to fund 422 projects (Jarren et al. 2017: 72, fig. 4).

In comparison with other countries, the Geisteswissenschaften (and, in fact, all sciences in Germany) can be considered fortunate, as there is substantial support by both public and private funding. Federal funding for research and development has been increasing, from 2005 to 2017 by around 90 per cent to $€ 17.2$ billion in 2017 (BMBF 2017: 9). State and private funding combined amounted to $€ 90$ billion in 2015, which makes Germany the strongest investor in research and development in the EU (30 per cent of all investments in research and development in the EU are made by Germany) (BMBF 2017: 9). In the BMBF budget report, the Geisteswissenschaften are combined with economics and social sciences: together they were allocated $€ 1.529$ billion in 2017 (€1.407 billion in 2016).

In 2016, the German Research Foundation (DFG), the central funding organization for science and research in Germany with an annual budget of over $€ 3$ billion, spent $€ 291.3$ million to support projects in the humanities (which marks a gradual increase from €256.9 million in 2014 and €273.3 million in 2015) (DFG 2017a: n.p.). As stated in the DFG funding fact sheet for 2016, following medicine and biology, the humanities are the third top DFG-funded area. This ranking, however, is misleading, as it compares the budget allocated to a single discipline (biology) with the budget allocated to the humanities at large.

In addition to the DFG, which - in terms of available funding - is the most important funding organization for the humanities, several private foundations have launched programmes tailored specifically to the Geisteswissenschaften. In 2016, the Volkswagen Foundation spent $€ 33.7$ million, more than half of their annual budget for research funding, on projects in the humanities and social sciences (VolkswagenStiftung 2017: 39, fig. 6). These include the opus magnum-fellowships, which provide scholars with sufficient financial support to be released from their teaching duties for up to 18 months to work on a monograph, or the Dilthey professorships, designed for early-career researchers who conduct innovative and potentially risky research projects. In addition, the Fritz Thyssen Foundation granted $€ 8.2$ million, half of their 
annual budget, to projects in the area of history, language, and culture (Fritz Thyssen Foundation 2017: n.p.). Further substantial support is provided by numerous exchange programmes for researchers, both on the early-career and advanced level, offered by the DFG, the German Academic Exchange Service, and especially the Alexander von Humboldt Foundation (AvH), which allow researchers to pursue their projects abroad while fostering the creation and consolidation of international networks by also supporting incoming researchers. In 2016, 24 per cent of the research fellowships granted by the Humboldt Foundation were awarded to researchers based in the humanities and social sciences (AvH 2017a), and most Humboldt Professorships, which enable renowned researchers from abroad to conduct long-term research in Germany, granted between 2012 and 2016, i.e. 15 in total, were won by scholars in the Geisteswissenschaften, which in the AvH funding overview also include professorships in psychology (1), the social sciences (1), and economics (2) (AvH 2017b: 83).

Considering these funding schemes, the 'crisis' might be regarded as a pseudo-crisis, self-inflicted by the humanities in response to increasing demands for applicability and looming bibliometric performance indicators demands that neglect the theoretical scope of the Geisteswissenschaften. Even within the humanities, the distinct theoretical scope is often viewed as a weakness rather than a strength, leaving the Geisteswissenschaften in an apologetic mode, which accelerates the escalating discussions of impact.

\section{There's the rub - the utility of knowledge}

Increasing concerns of applicability continue to haunt the Geisteswissenschaften. In fact, as Hans Ulrich Gumbrecht recently argued countering Marquard's claim, the Geisteswissenschaften are by no means 'indispensable', but rather an also-ran by the majority of society, whose disappearance most educated people would not even notice (Gumbrecht 2015: 4). Compared with the natural sciences or engineering, the 'inevitability' of the humanities might indeed be less apparent, as their findings are less tangible than in other subject areas. The same, however, could be claimed for so-called basic research in the natural sciences, whose outcomes are rarely visible and whose impact can hardly be communicated to the tax-payers.

Nonetheless, 'usefulness' is a category that continues to dominate public discourse and informs the rationale of most research and teaching institutions: "[u]niversities have been so reorganized that they have become tools of those who believe in a special political [or] economic, ... creed” (Flexner 1939: 550). Though published in spring 1939, this statement by Abraham Flexner, founder of the Institute for Advanced Sciences in Princeton, has striking relevance today. And yet, as Flexner stressed, many if not most of the greatest discoveries emerged from seemingly 'useless' research, unguided by extrinsic motivation, not targeted to a specific application, and only realized as highly 'valuable' in 
retrospect. Hence, he claimed that "out of this useless activity there come discoveries which may well prove of infinitely more importance to the human mind and to the human spirit than the accomplishment of the useful ends for which the schools were founded" (Flexner 1939: 549). What is needed for innovation, therefore, are resources, time, and also trust, more precisely, as Helmut Schwarz, former President of the Humboldt Foundation, argued, "[t]he principle of trusting people rather than trusting a monitoring system based on distrust" (Schwarz 2017: 3). These are increasingly rare and valuable currencies in today's economy of attention. Even though the humanities still need to work harder to communicate aspects of their research to the greater public and engage more vividly in public discourses and self-marketing to obviate debates on their 'relevance', it is surprising that categories such as 'inevitability', 'relevance', or 'usefulness' seem to experience a comeback.

While the reduction of science to impact factors is a lamentable trend that fortunately has not hit Germany as heavily as, for instance, the UK, the discussion on impact sets the scene for leading funding programmes, such as European Commission's Horizon 2020. Of the 'grand challenges' defined in the Horizon 2020 funding programme - i.e. health, food security, renewable energy, green transport, climate action, or secure societies - the humanities (and social sciences) can merely respond to an additional area, i.e. "Europe in a changing world - inclusive, innovative and reflective societies", which is not listed among the six top societal challenges (European Commission 2013: 146), but appears as an addendum to open up the programme to further disciplines. While the European Science Foundation is deeply committed to promoting interdisciplinary projects in all fields of science and repeatedly stressed the "broad relevance" of research in the humanities and social sciences also in connection with other challenges, the notion that these disciplines could analyse the behavioural, cultural, economic, and institutional changes necessary for reforming health and transport systems or serve as "an essential source for creativity in development of services and product design" (European Commission n.d.: n.p.), is still somewhat reminiscent of Marquard's claim and might further support the impression that Geisteswissenschaften are not a science amongst sciences, but rather serve as auxiliary sciences.

And yet, further funding schemes, such as, for instance, the open-topic ERC Starting, Consolidator, and Advanced Grants, tell a different story, as grants are awarded based on excellence of the project and the Principal Investigator only. Nonetheless, even with these grants, "a rough formula exists, of distributing project funds in an 85:15 proportion in favour of STEM [science, technology engineering and medicine] disciplines when compared to the social sciences and humanities" (Hoenig 2017: 20). Hence around 80 per cent of the overall budget is awarded to STEM-disciplines, only 20 per cent to social sciences and humanities (Hoenig 2017: 175).

The significant disparity in funding, also apparent in DFG-programmes, is in itself not a matter of concern: it rather reflects the low-cost research 
tradition in the humanities, which do not need elaborate lab equipment or expensive technologies. Instead, funding is needed to conduct archival work, to secure access to library resources, or foster international exchange (fellowships, research stays abroad), or finance a team of PhD-students and Postdocs to assist in research projects. Having said that, the costs for research in the humanities have gradually increased, driven by the recent emphasis on more experimental and empirical approaches, as conducted, for instance, in the field of Empirical Aesthetics, and the new research infrastructures needed in the growing area of Digital Humanities. Both areas are currently experiencing a boom in the German research landscape: the first was being pushed by the foundation of a Max-Planck-Institute in Frankfurt, founded to enable interdisciplinary research that brings together the humanities, especially linguistics, literary studies, and musicology, and the neurosciences. The second was supported by the European Commission to facilitate knowledge preservation and transfer by establishing a European Network for Digital Research Infrastructure (DARIAH), designed to boost (inter)national collaboration, take research in the humanities to the next level and also enhance their impact by enabling the production of visible, quantifiable, and also marketable results.

These funding schemes tailored to a specific area are boon and bane: while they initiate new areas of research, aid the development of novel methodologies, and offer substantial support to otherwise under-funded areas, they heavily intervene in research agendas and jeopardize the academic freedom and curiosity-driven research from which innovation can arise. The DHboom has led to the implementation of new professorships in this area, but it has also increased the pressure on the 'traditional humanities' to engage in big-data projects to keep in touch with the big funding pots.

As often claimed by humanities researchers, however, their most important resource, besides access to well-equipped (online) archives and people, is time. Though this might sound presumptuous, as time is indispensable for all innovation, research in the Geisteswissenschaften more than in any other field still is a highly individual endeavour, focused on individual research activities, often published in a monograph or single-authored article. In Germany, most funding programmes have responded to these discipline-specific needs by providing funds that are designed to allow (early-career) researchers to be released from administrative (and teaching) duties in order to focus on their individual projects, such as the BMBF-initiative Freiräume or the Freigeist- or opus maximum-programmes by the Volkswagen Foundation.

\section{Between Bildung and Ausbildung}

Though frequently overlooked, the greatest societal impact of the Geisteswissenschaften lies in their seminal role in higher education programmes - in teaching. In addition to fostering creative and critical thinking, and enabling a deep understanding of different languages, histories, and cultures - aspects 
that seem far too general to attribute them to the humanities only - many students enrolled in the Geisteswissenschaften are training to become teachers in secondary education. Disciplines, such as English or German studies, for instance, gain in 'legitimacy' due to their important role in teacher-training programmes. In fact, at some universities (especially technical or technically oriented universities), the humanities often survive only because they are the key to a research-oriented education of secondary school teachers and their position is defended by the respective ministry for education to secure future Bachelor or Master of Education programmes. Geisteswissenschaften, however, cannot be reduced to Ausbildung, to mere vocational training, but they perfectly combine both aspects of education, Bildung and Ausbildung, which can be rudimentarily translated with 'cultivation' and 'education': they reflect upon knowledge, value systems, and cultural processes and thereby provide critical insight into the mechanisms that determine our worlds of life. Technical universities, in particular, dominated by natural science and engineering, tend to underestimate what is gained by the Geisteswissenschaften, thus jeopardizing what John Hennessy, President of Stanford University, referred to as "the intellectual ring, the intellectual buzz of the universities" (quoted from Gumbrecht 2015: 20) which the humanities provide.

Based on enrolment numbers, there is no immediate crisis. In fact, data suggests the opposite: through 2014, student numbers in the Geisteswissenschaften (excluding Psychology and Pedagogy) rose unabated from 301,984 in the academic year $2009 / 2010$ to 342,928 (87,146 first-semester students) in $2016 / 2017 .{ }^{1}$ Despite this increase in absolute numbers, viewed in relation to the total number of students enrolled at German universities $(2,807,010$ in $2016 / 2017$ and 2,847,821 in 2017/2018), the percentage of students studying Geisteswissenschaften dropped from 14.2 per cent in 2009/2010 to 12.2 per cent in 2016/2017. And yet, refuting allegedly low employment perspectives, students have not been flocking to the STEM disciplines to obtain a more 'promising' degree in science, technology, engineering, and mathematics. The crisis in the humanities first and foremost arises from the high teaching and supervision load, based on a poor student-professor ratio.

Though the number of students in the Geisteswissenschaften has grown steadily since 1997, the number of professors has remained relatively stable (with some losses in disciplines, such as Classics and East-European History, and some gains, for instance, in Gender Studies, Islamic Studies, or Digital Humanities) while the number of Assistant Professors (Wissenschaftliche Assistenten) and non-professorial faculty, the so-called Mittelbau, with heavier teaching loads, has even dropped (Herbert 2007: n.p.). As a consequence, the number of students admitted to courses has extended, seminars that were traditionally dedicated to offering a forum for in-depth discussions of current research have been transformed into lectures with no to little room for active student participation, and the student-professor ratio increased from an average of $72: 1$ in 2009 to an average of 74:1 in 2016. Due to differences 
within the federal system, this ratio differs dramatically between individual states or Länder, ranging from 51.5:1 (Mecklenburg-Vorpommern) to 99:1 (North Rhine-Westphalia). As shown in a recent review of the development of the student-professor ratio between 2010 and 2014, Cultural Studies and Linguistics $(81: 1)$ tends to have the third-worst ratio, topped only by Law, Economics, and Social Sciences (100:1) and Engineering (93:1) (IEKE 2016: 14, fig. 3). These modest ratios might contribute to the high drop-out rate in the humanities (including the social sciences): around 30 per cent of all students enrolled in a Bachelor's programme in languages or cultural sciences, for instance, withdraw from their studies. And yet, the grass is not greener in the natural sciences: subjects, such as maths (51 per cent), computer science (45 per cent), chemistry (42 per cent), or physics (40 per cent) have to cope with even higher numbers of drop-outs. ${ }^{2}$ Though Master programmes are generally less affected by drop-outs (15 per cent between 2012 and 2014), only 25 per cent of MA-students studying languages or cultural sciences eventually finish their degrees (Heublein et al. 2017: 264). On the other hand, the drop-out rate for students studying for a teaching degree in secondary schools (state examination) is moderate (13 per cent). Due to the recent reforms of study programmes, however, these numbers can only indicate coarse trends. Students enrolled for a Bachelor or Master of Education, for instance, were not considered in this study. Nonetheless, the results suggest that clearly defined employment prospects might lower the drop-out rates.

With regard to teaching, a major turning point in the Geisteswissenschaften was the Bologna reform, which aimed to introduce new structures analogous to the Anglo-American system to enable comparability, greater transparency, increased international exchange, and more efficient and coherent study programmes. One major difference to previous study programmes is the focus on a single discipline (in contrast to previous combinations of one major with two minors). Though designed with the intent to increase flexibility, the revised study programmes often turn out to be extremely rigid especially regarding course contents. Set module descriptions, which are specified in study guidelines, can hardly be reconciled with the freedom of teaching and can scarcely accommodate research-driven seminars, which cannot be outlined years in advance. Further, increased specialization within BA- or MAprogrammes bears some risk - not so much for students, but for the departments and faculties offering them, as they are often tied to the expertise of current faculty. In small departments where the teaching and research duties are divided amongst just a few staff members, specialization in teaching programmes is almost impossible. As a consequence, course descriptions are kept as vague as possible, making them superfluous. In turn, due to a lack of focus, especially in the Master programmes, student enrolments are scarce. While faculties in the humanities with reasonable large faculty strength might have benefitted from the Bologna reform, smaller disciplines are struggling to keep or attract students. 
Finally, due to the rigid timetables in BA- and MA-programmes, students are much more confined in their choice of courses and also less willing to attend courses that do not feed their Bachelor- or MA-accounts with the desired ECTS points. Instead of improving research-oriented education, Bologna has opened up a bazaar economy where bargaining for ECTS credits becomes a routine. Rushing students to complete their BA-degree in six semesters, these programmes leave little room for developing critical perspective, acquiring deeper understanding of one's field of study (especially in subjects that demand competencies in foreign languages which cannot be attained in three years), or broadening the perspective by spending some time abroad. Ironically, the Bologna reform has radically reduced rather than enhanced international exchange, as students feel increasingly pressured not to 'lose' any time by studying abroad and driven into a low-risk-low-gain mentality.

\section{The crisis of excellence}

In the 2006 report on the development of the Geisteswissenschaften, the German Research Council came to the conclusion that there is no real crisis: the international reputation of the Geisteswissenschaften has been consistently good, certainly comparable to the natural sciences; the employment rate for graduates in the humanities and social sciences (73 per cent) five years after graduation approximated the average employment rate across all disciplines (89 per cent); and the number of independent research institutions, established by the Max Planck Association and the Leibniz Association and dedicated to supporting the humanities, was deemed adequate (Wissenschaftsrat 2006: 7-10). Others, however, argued that at the time of the report, the Geisteswissenschaften had already compensated the severe cuts and decreasing financial resources, which resulted, for instance, from the reduction of academic personnel in the course of the salary reform in 1990 (Gruner 2007: 102). In addition to a basic salary, professors' salaries increasingly depend upon performance indicators that are often restricted to the (prospective) acquisition of third-party funding or to impact, which in the humanities is more difficult to assess than in most natural sciences and engineering. Since the publication of the mentioned report, a new crisis emerged, triggered by the increased competition for both third-party funding and the seal of 'excellence'.

In the decentralized and federal system of Germany, responsibility for higher education lies primarily in its 16 states (Länder). As the Länder's expenditure or basic funding for universities has stagnated for the past 15 years, universities are increasingly dependent on third-party funding to maintain high standards in both research and teaching. It is against this backdrop that the Federal and State governments launched the so-called Excellence Initiative (EI) in 2005, a national, solely performance-oriented competition 
for additional funding, with a total budget of $€ 4.6$ billion. The aim was to strengthen Germany's position as a centre of science and research, make its universities more competitive internationally (especially by enhancing the conditions for early-career researchers and expanding collaborations between universities and further scientific institutions), and identify the top universities, i.e. up to ten 'universities of excellence' within the German scientific landscape.

The Initiative, which comprised two rounds of funding (running for five years each), included three funding lines to support (1) the foundation of Graduate Schools or Centres to support early-career researchers, (2) Clusters of Excellence to enhance top-notch research, and (3) Institutional Strategies to support selected universities with a strong and promising research profile in establishing themselves as internationally renowned research hubs. While proposals for Graduate Schools and Clusters of Excellence could be submitted by all universities, only universities who were awarded at least one Graduate School and one Cluster were eligible to submit an Institutional Strategy and enter the competition for the title of 'University of Excellence'.

Whether the Excellence Initiative has achieved its aim to increase the international visibility of German research is difficult to assess. Though highly contested, one possible metric for testing its 'success' was suggested to be bibliometrics. Indeed, the number of publications in highly cited journals have increased at universities with funded excellence clusters. Viewed in relation to the total number of international publications, however, the percentage of German publications in general and highly cited publication, in particular, has slightly dropped from 6.0 to 5.1 per cent and 6.9 to 6.3 per cent respectively (Hornbostel and Möller 2015: 37). In the sense that it is not reflected in bibliometric data, the Initiative's aim to noticeably increase the international visibility of research conducted in Germany has not been reached (Hornbostel and Möller 2015: 48f.). This little insight offered by bibliometrics, however, proves a point: first, it is symptomatic that publications in the Geisteswissenschaften were not included in this study due to their limited coverage. The web of science includes only peer-reviewed articles. This is a problem for the humanities, as key publications in the humanities are not only (peerreviewed) journal articles, but monographs and edited volumes, which though peer-reviewed - are often not covered by bibliometrics nor the web of science. Second, and more significantly, the quality and excellence of research cannot be measured. As argued in a recent joint statement by the Académie de Sciences, the German National Academy of Sciences Leopoldina, and the Royal Society, alt- or bibliometric indicators "also hinder the appreciation of the work of excellent scientists outside the mainstream" and may even "encourage ... 'citation clubs" to promote "mutual citation" (2017: 2).

Undoubtedly, the Excellence Initiative changed the academic landscape: in the first funding period (2007-2012), 45 Graduate Schools, 43 Clusters of Excellence, and 11 Institutional Strategies were funded; numbers in the 
second round (2012-2017) slightly dropped to 39 Graduate Schools, 37 Clusters of Excellence, and nine Institutional Strategies. In both rounds combined, one-third (36 per cent) of the Graduate Schools, but only 16 per cent of the Excellence Cluster were based in the Geisteswissenschaften (cf. DFG 2013). While the latter gained in support of early-career researchers, they have fallen behind in the attempt to establish international research hubs, which corroborated the still wide-spread image of 'the lone researcher' unwilling to engage in collaborative research. In fact, the Initiative has frequently been criticized for neglecting the specificities of research in the humanities, as big structural models, such as research clusters, are common in the natural and life sciences, but often inadequate for research in the humanities (Möller et al. 2012: 12). Though collaboration and exchange are vital in all areas of research, big structural models, such as clusters, are not always needed in the humanities to yield high-end results.

The considerable success of the Geisteswissenschaften in the acquisition of funding for Graduate Schools, on the other hand, is symptomatic of the field and the precarious situation of early-career researchers especially in the humanities where, unlike in the natural and life sciences, (part-time) employment of doctoral students is as rare as their integration in (existing) labs or research groups.

These shortcomings could have been corrected in the additional, final round of funding, dubbed 'Excellence Strategy', launched in 2018 with an annual budget of $€ 533$ million. ${ }^{3}$ Based on a review of the previous initiative, Graduate Schools are no longer included in the funding scheme. Instead, those funded in the first two rounds will be sustained by the universities who committed to implementing them permanently. The focus, therefore, is solely on research clusters and the run for the title of 'University of Excellence' to strengthen individual universities or consortia with further research institutions. To be eligible to apply for the prestigious title, universities must be successful in acquiring funding for at least two clusters. To date, 88 (from 196) proposals have been selected for the second round, 29 per cent of which are based in the humanities. To what extent the humanities are strengthened by the Excellence Strategy remains to be seen: the final decision which of these clusters will be funded is expected for September 2018.

As remarked by Dieter Imboden, chair of the EI review committee, while the funding programme has "brought German science some structural change[,] its achievements must not obscure the view of its flaws" (Münch quoted in Schiermeier 2017: n.p.). One of the flaws is its temporary scope: universities are critically underfunded, but their basic funding will not increase and only a happy few will profit from the initiative for a limited time. Another is the political tinge of the programme. Devised and financed by Federal and State governments (75 per cent Federal and 25 per cent State funding), it may be assumed that there is a strong interest in distributing cluster funding rather equally between the 16 states: the 88 cluster proposals 
still in the race are grounded in 41 universities from 13 states. Though the selection committee will consist of independent, international scholars, Federal and State ministers will also be present. It will be the responsibility of the committee to dismiss any political considerations that might impact the selection process.

A further inherent problem that might pave the ground for yet another severe crisis of the Geisteswissenschaften is the increasing clustering of science, boosted by these funding programmes. This might result in a mainstreaming of science, in which not only the Geisteswissenschaften will continue to lose ground. Academic excellence arises from diversity and from the support of individual researchers: it can neither be planned nor clustered. As stated by Richard Münch in relation to the EI, "the combination of variety and competition, part of federal pluralism, is being superimposed by trends towards the formation of oligopolies and monopolies" (Münch 2014: 91).

The biggest flaw, however, is the label of the 'University of Excellence', which will be granted partly based on the success of the cluster proposals and assigned to a maximum of 11 universities only. These distinguished universities will receive additional financial support of $€ 10-15$ million/annum and will be reviewed again after seven years. To what extent the success of two research clusters can serve as an indication of excellence which is henceforth grafted onto universities as a whole is highly debatable. Furthermore, it would be hard to justify why the happy few universities that were already awarded the seal of excellence in the EI might lose it again after only seven years. On the other hand, a mere confirmation of their excellence would culminate in an academic theatre of the absurd.

Universities that have won the seal of excellence were often referred to as 'lighthouses of science', a highly infelicitous term, as it implies that the majority of research institutions in Germany inhabit a heart of darkness: excellence is an achievement bound to individual researchers, their motivation, and expertise. Hence, it is on the move and can hardly be engraved onto specific departments, faculties, or universities. The underlying aim to elect a German Oxford or Harvard ultimately fails to do justice to the German academic landscape: first, because universities in Germany are critically underfunded (unlike private universities which can draw on student fees, German universities have largely abandoned the small fees once introduced). Second, because the university system is characterized by greater mobility than, for instance, the Anglo-American system.

Due to a missing promotion and structured tenure-track system, not only professors tend to change places in order to improve their research facilities and also their salary: postdoctoral researchers, often the driving forces in topnotch research projects, are frequently faced with temporary, often precarious, contracts, which increase (involuntary) mobility. It is one of its (negative) side effects that the Excellence Strategy - like the EI - will lead to an increase of temporary positions, especially on the doctoral and postdoctoral level, 
which will intensify the precarious job situation for early-career researchers in academia.

To improve the situation of early-career researchers, the Federal and State governments have initiated a funding programme that supports the implementation of 1,000 tenure-track professorships in Germany: as part of the programme, funding for the first six years of these professorships is provided as an incentive for universities to permanently implement tenure-track professorships. It remains to be seen to what extent this measure will alleviate or intensify the 'crisis' of the Geisteswissenschaften. As individual faculties were expected to provide long-term perspectives for these professorships but are critically underfunded, common solutions included the downgrading of full professorships (W3) to tenure-track professorships (W1) - a zero- (or negative-) sum situation, which might, in the long run, further weaken the Geisteswissenschaften and, in particular, the so-called small disciplines, which often consist of only one single full professorship.

\section{Post- or pre-crisis?}

The discussion of their own crises has become the form of life of the Geisteswissenschaften (Gumbrecht 2017: 2:24-2:26). However, if crises are productive, then they should be intrinsic to all disciplines. If one of the key tasks of the humanities is 'to complexify' the world (Gumbrecht 2017: 3:09) or to engage in 'understanding understanding' (Seel 2004), the crisis is an inevitable component that arises from the critical reflection upon the foundations, approaches, and findings of individual disciplines. It is to be nourished, not overcome. To what extent the Excellence Initiative and the Excellence Strategy had or will have a positive impact on the humanities remains to be seen. The fact that there was and is additional funding available that is allocated based on a national competition cannot be deemed anything but a positive development. And yet, the main funding lines do not acknowledge the fact that the humanities to a greater extent than other disciplines rely on individual research (and single-authored publications) rather than research clusters. As a result, there is a growing trend across the Geisteswissenschaften to adopt practices from the natural sciences and engineering, such as, for instance, establishing 'labs' for specific research projects. While some areas, such as empirical aesthetics, will profit from this development, especially the 'small' disciplines that do not and, due to their limited personnel, cannot succumb to the increasing pressure of clustering will be increasingly marginalized and, due to further looming cuts that will hit them first, threatened in their existence.

The BMBF and several foundations in Germany have already reacted to this threat and designed programmes tailored to small disciplines and the support of individual researchers beyond the tendencies towards clustering science. While the humanities cannot meet the alleged 'grand challenges', they 
tackle fundamental challenges of our Lebenswelt. They can do so due to their theoretical and methodological plurality and the diversity of disciplines and research traditions, which need to be acknowledged and sustained.

In the long run, programmes such as the Excellence Initiative or Strategy might indeed not advance the condition of the Geisteswissenschaften. Longterm improvement will be achieved only if the deficits of these programmes, including the sole focus on grand structures, applicability, and immediate usability of knowledge, are recognized as such, which might lead to an amendment of funding policies in Germany (cf. Turner 2007: 446). Ironically, the recognition of these deficits seems contingent on crisis - a crisis that revolves around the obsession with 'useful knowledge' and with impact. This crisis can provide new opportunities for curiosity-driven, risk-taking projects that are based on individual, not institutional excellence, and acknowledge the strong ties between research and teaching. If such a crisis can lead to a reimagining of the role of the Geisteswissenschaften, then there is, and there should be, a crisis of the humanities in Germany. Without it, the trends towards clustering and an increased focus on the technical and natural sciences will continue to marginalize the Geisteswissenschaften, and with it, to quote Hennessy again, "the intellectual ring, the intellectual buzz of the universities". And then, indeed, "the rest is silence" (Hamlet, 5.2.363).

\section{Notes}

1 Student numbers are taken from the Federal Statistical Office (www.destatis.de).

2 These numbers are based on a survey, based on enrolments in the academic years 2006/2007, 2008/2009, and 2010/2011 and the respective degrees awarded in 2010, 2012, and 2014 (Heublein et al. 2017: 264; www.dzhw.eu/pdf/pub_fh/fh-201701.pdf).

3 In addition, it was agreed to increase financial support for the science organizations, which are jointly funded by Federal and Länder governments, i.e. Max Planck Society, Helmholtz Association, Leibniz Association, Frauenhofer Society, German Research Association as part of the Pact for Research and Innovation. Between 2016 and 2020, an additional $€ 3.9$ billion will be granted by the Federal government as part of this Pact. www.research-in-germany. org/en/research-landscape/r-and-d-policy-framework/pact-for-research-and-innovation. html.

\section{References}

Académie des Sciences, Leopoldina, Royal Society (2017) 'Statement by Three National Academies (Académie des Sciences, Leopoldina and Royal Society) on Good Practice in the Evaluation of Researchers and Research Programmes'. Accessed 19/12/2017. www.leopoldina.org/ uploads/tx_leopublication/2017_Statement_3Acad_Evaluation.pdf.

AvH/Alexander von Humboldt Foundation (2017a) 'Fellowships and Grants Awarded in 2016'. Accessed 19/12/2017. www.humboldt-foundation.de/web/statistik.html.

AvH/Alexander von Humboldt Foundation (2017b) Jahresbericht 2016, Bonn-Bad Godesberg, AvH. Accessed 19/12/2017. www.humboldt-foundation.de/web/docs/F2085718550/ jahresbericht_2016.pdf.

BMBF/Federal Ministry for Research and Education (2017) Bildung und Forschung in Zahlen 2017. Accessed 19/12/2017. www.datenportal.bmbf.de/portal/de/brochure.html. 
Brown, Marshall (1997) Turning Points: Essays in the History of Cultural Expressions, Stanford, Stanford University Press.

Bulhof, Ilse N. (2012) Wilhelm Dilthey: A Hermeneutic Approach to the Study of History and Culture, The Hague, Springer.

DFG/German Research Foundation (2013) Exzellenzinitiative auf einen Blick. Der Wettbewerb des Bundes und der Länder zur Stärkung der universitären Spitzenforschung. Bonn: DFG. Accessed 19/12/2017. www.dfg.de/download/pdf/dfg_im_profil/geschaeftsstelle/ publikationen/exin_broschuere_de.pdf.

DFG. (2017a) Facts and Figures 2016. Accessed 19/12/2017 www.dfg.de/download/pdf/dfg_im_ profil/geschaeftsstelle/publikationen/flyer_zahlen_fakten_en.pdf.

DFG. (2017b) Jahresbericht 2016. Aufgaben und Ergebnisse. Accessed 19/12/2017. www.dfg.de/ download/pdf/dfg_im_profil/geschaeftsstelle/publikationen/dfg_jb2016.pdf.

Dill, Hans-Otto (2013) Alexander von Humboldts Metaphysik der Erde. Seine Welt-, Denk- und Diskurskonstruktionen, Frankfurt a.M., Peter Lang.

European Commission (n.d.) 'Horizon 2020: Social Science \& Humanities'. Accessed 5/12/2017. https://ec.europa.eu/programmes/horizon2020/en/area/social-sciences-humanities.

European Commission (2013) The Grand Challenge: The Design and Societal Impact of Horizon 2020, Luxembourg, Publications Office of the European Union.

Flexner, Abraham (1939) 'The Usefulness of Useless Knowledge'. Harpers, 179: 544-552.

Fritz Thyssen Foundation (2017) 'Figures, Data and Facts'. Accessed 5/12/2017. www.fritzthyssen-stiftung.de/en/about-us/general-information/zahlen-daten-fakten/.

Frühwald, Wolfgang, Hans Robert Jauß, Reinhart Koselleck, Jürgen Mittelstrass, and Burkhart Steinwachs (eds) (1991) Geisteswissenschaften heute. Eine enkschrift, Frankfurt a.M., Suhrkamp.

Gauger, Jörg-Dieter (2007) Warum die Geisteswissenschaften Zukunft haben! Ein Beitrag zum Wissenschaftsjahr 2007, Freiburg, Herder.

Gruner, Wolf D. (2007) 'Krise der Geisteswissenschaften? Ihre Stellung und Rolle, insbesondere die der Geschichtswissenschaft in Deutschland im Vergleich mit Frankreich, Großbritannien und den USA'. In: Gauger: 66-134.

Gumbrecht, Hans Ulrich (2007) 'Der Luxus des Freien Denkens'. Frankfurter Allgemeine Zeitung, 10 January. Accessed 19/12/2017. www.faz.net/aktuell/feuilleton/geisteswissenschaften/ jahr-der-geisteswissenschaften-der-luxus-des-freien-denkens-1405622.html.

Gumbrecht, Hans Ulrich (2015) 'Die ewige Krise der Geisteswissenschaften - und wo ist ein Ende in Sicht?' Beiträge zur Hochschulpolitik 4. Accessed 19/11/2017. www.hrk.de/fileadmin/ redaktion/hrk/02-Dokumente/02-10-Publikationsdatenbank/Beitr-2015-04_Gumbrecht_ Krise_Geisteswissenschaften.pdf.

Gumbrecht, Hans Ulrich (2017) 'Humanities: Are Humanities in Crises'. Panel Discussion. University of Luxembourg, 10 July. Accessed 19/12/2017. wwwen.uni.lu/flshase/actualites/ talk_humanities_are_humanities_in_crisis

Herbert, Ulrich (2007) 'Kontrollierte Verwahrlosung'. Die Zeit, 30 August. Accessed 19/12/2017. www.zeit.de/2007/36/B-Geisteswissenschaft.

Heublein, Ulrich, Julia Ebert, Christopher Hutzsch et al. (2017) Zwischen Studienerwartungen und Studienwirklichkeit, Forum Hochschule 1 et al., Hannover, Deutsches Zentrum für Hochschul- und Wissenschaftsforschung.

Hoenig, Barbara (2017) Europe's New Scientific Elite: Social Mechanisms of Science in the European Research Area, Milton, Routledge.

Hornbostel, Stefan (2014) 'Schisma oder Diversifikation. Das Verhältnis von Natur-, Sozial- und Geisteswissenschaften'. In: Geistes- und Sozialwissenschaft an der Universität von morgen: Innenansichten und Außenperspektiven, Mechthild Dreyer, Uwe Schmidt, Klaus Dicke (eds), 99-124, Wiesbaden, Springer.

Hornbostel, Stefan, and Torger Möller (2015) Die Exzellenzinitiative und das deutsche Wissenschaftssystem: Eine bibliometrische Wirkungsanalyse, Berlin, Berlin-Brandenburgische Akademie der Wissenschaften. 
IEKE/International Expert Commission on the Excellence Initiative (2016) Internationale Expertenkommission zur Evaluation der Exzellenzinitiative: Endbericht. Accessed 19/11/2017. www.gwk-bonn.de/fileadmin/Papers/Imboden-Bericht-2016.pdf.

Jahraus, Oliver (2007) 'Sinn und Eigenrecht der Geisteswissenschaften'. In: Gauger: 242-253.

Jarren, Otfried, Sibylle Baumbach, Friedrich Wilhelm Graf, Steffen Mau, Barbara Mittler, and Sönke Neitzel (2017) Evaluierung des BMBF-Rahmenprogramms 'Geistes-, Kultur- und Sozialwissenschaften': Abschlussbericht. Accessed 19/12/2017. www.bmbf.de/files/GKS_ Evaluationsbericht_Final.pdf.

Krieger, Regina (2006) 'Krise? Welche Krise?' Handelsblatt, 22 November. Accessed 19/12/2017. www.handelsblatt.com/technik/forschung-innovation/geisteswissenschaften-krise-welchekrise/2736328.html.

Lepenies, Wolf (1998) Between Literature and Science: The Rise of Sociology, trans. R.J. Hollingdale, Cambridge, Cambridge University Press.

Markschies, Christoph (2006) 'The Future of the Humanities'. Accessed 5/12/2017. www.huberlin.de/de/ueberblick/geschichte/rektoren/markschies/rede/talk_humanities.

Marquard, Odo (2001) 'Über die Unvermeidlichkeit der Geisteswissenschaften'. Apologie des Zufälligen. Philosophische Studien, Stuttgart, Reclam: 98-116.

Metten, Thomas (2016) 'Konturen der Kulturwissenschaft/en - einleitende Überlegungen'. Kulturwissenschaftliche Zeitschrift 1/1: 5-16.

Mittelstrass, Jürgen (2013) Schöne Neue Leonardo-Welt: Philosophische Betrachtungen, Berlin, Berlin University Press.

Möller, Torger, Philipp Antony, Sybille Hinze, and Stefan Hornbostel (2012) Exzellenz Begutachtet: Befragung der Gutachter in der Exzellenzinitiative. iFQ-Working Paper 11. Accessed 19/11/2017. www.forschungsinfo.de/publikationen/Download/working_paper_ 11_2012.pdf.

Münch, Richard (2014) 'Faded Grandeur: Disciplinary Differentiation, Interdisciplinarity and Renewal in the German Academic System'. In: The Institution of Science and the Science of Institutions, Marcel Herbst (ed.), 83-102, Dordrecht, Springer.

Nida-Rümelin, Julian (2006) Humanismus als Leitkultur: Ein Perspektivenwechsel, Munich, Beck. Rickert, Heinrich (1926) Kulturwissenschaft und Naturwissenschaft, Tübingen, Mohr.

Schiermeier, Quirin (2017) 'Plans to Promote German Research Excellence Come Under Fire'. Nature 551(7678). Accessed 19/12/2017. www.nature.com/news/plans-to-promotegerman-research-excellence-come-under-fire-1.22921.

Schwarz, Helmut (2017) 'On the Usefulness of Useless Knowledge'. Nature Reviews. Chemistry $1,1-3$.

Seel, Martin (2004) 'Weltverstrickt. Das Verstehen verstehen. Über den Sinn der Geisteswissenschaften'. Die Zeit, 22 April. Accessed 19/12/2017. www.zeit.de/2004/18/GW-Seel.

Shakespeare, William (2000 [1982]) Hamlet. Ed. Harold Jenkins, London, Arden.

Snow, C.P. (1998 [1959]) The Two Cultures, Cambridge, Cambridge University Press.

Turner, George (2007) 'Exzellenzinitiative und Geisteswissenschaften'. In: Gauger: 436-446.

VolkswagenStiftung (2017) Jahresbericht 2016. Accessed 19/12/2017. www.volkswagenstiftung. de/aktuelles-presse/publikationen/publdet/news/detail/artikel/jahresbericht-2016/ marginal/5313.html.

Wissenschaftsrat (2006) Empfehlungen zur Entwicklung und Förderung der Geisteswissenschaften in Deutschland, Cologne, Wissenschaftsrat. Accessed 19/12/2017. www.wissenschaftsrat. de/download/archiv/geisteswissenschaften.pdf. 